九州大学学術情報リポジトリ

Kyushu University Institutional Repository

\title{
Application of Sodium Silicate Chemical Grouting to Tropical Regions
}

Shimada, Hideki

Department of Earth Resources Engineering, Faculty of Engineering, Kyushu University : Professor

Wahyudi, Sugeng

Department of Earth Resources Engineering, Faculty of Engineering, Kyushu University : Assistant Professor

Sasaoka, Takashi

Department of Earth Resources Engineering, Faculty of Engineering, Kyushu University : Associate Professor

Hamanaka, Akihiro

Department of Earth Resources Engineering, Faculty of Engineering, Kyushu University : Assistant Professor

他

http://hdl. hand le. net/2324/4355470

出版情報: Springer Series in Geomechanics and Geoengineering, pp.390-398, 2019-11-30. Springer Nature

バージョン：

権利関係 : 


\title{
Application of Sodium Silicate Chemical Grouting to Tropical Regions
}

\author{
Hideki Shimada ${ }^{10000-0001-8410-2749]}$, Sugeng Wahyudi ${ }^{10000-0001-9856-6421]}$, Takashi \\ Sasaoka $^{1}$, Akihiro Hamanaka ${ }^{10000-0001-7600-417 X]}$, Yasuharu Toshida ${ }^{2}$ and Tomohiko \\ $\mathrm{Abe}^{3}$ \\ ${ }^{1}$ Kyushu University, Fukuoka 819-0395, Japan \\ 2 Toso Sangyo Co. Ltd., Chiyoda, Tokyo 102-0067, Japan \\ ${ }^{3}$ Nittoc Construction Co. Ltd., Chuo, Tokyo 104-0061, Japan \\ shimada@mine.kyushu-u.ac.jp
}

\begin{abstract}
Considering to sustainable land use following mine closure has a critical role in achieving green mining objective, ground improvement particularly in slope and tailing pond is sometimes necessary to define competency in ground engineering. One of the methods that applied in ground engineering is chemical grouting. Unfortunately, there is no any established chemical grouting for tropical soil type, which is acid or alkaline. Four decades ago, a chemical grouting for tropical soil was developed in Indonesia. However, this chemical grouting has completely been prohibited by the Indonesian government after the grouting is identified generates polymeric chemicals pollution. A new safe formula of chemical grouting must be found, and this paper investigates the applicability of the chemical grouting of sodium silicate chemicals in tropical region. In the experiment, the chemical grouts were injected into Indonesian sands. After solidification of the chemical grouts, coefficient of permeability was measured by falling head hydraulic conductivity test. As the conclusion, it is indicated that the sodium silicate chemical grouting is useful to improve tropical acid soil environmentally friendly.
\end{abstract}

Keywords: Chemical Grouting, Sodium Silicate, Alkaline.

\section{Introduction}

Ground engineering has a critical role in achieving green mining objectives [1]. This keynote address present throughout the whole life cycle of a mining operation, from operation through to mine rehabilitation and closure. Experience, such as the failure of the tailings dam at Samarco Mine in Brazil in November 2015 [1] has demonstrated the critical role of ground engineering and show the ground control is a core risk in mining particularly in slope stability and tailing pond. The chemical grouting is one of the ground improvements that improves the strength and permeability of the ground (Fig. 1). This method has several superiorities in terms of the application, but if the grouting is not well developed in accordance with the soil type such as tropical soil, it will be a problem to environment. 


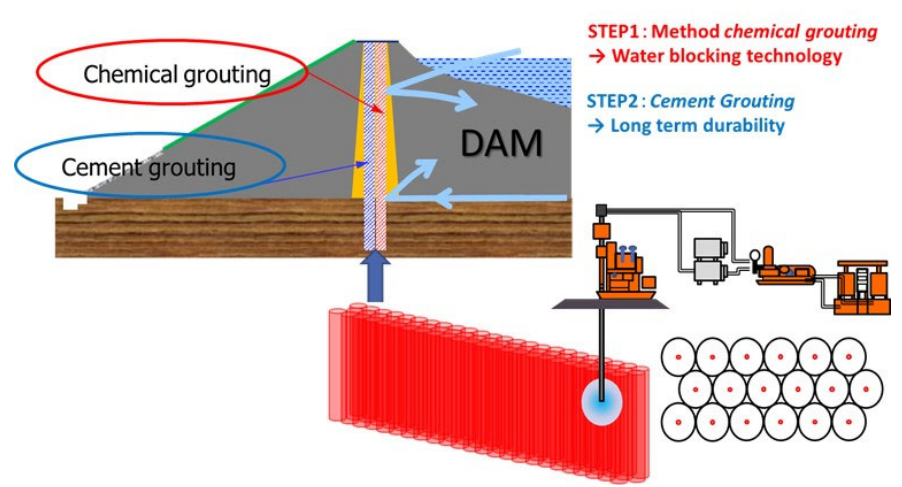

Fig. 1. Chemical grouting application on tailing pond.

In 1975, the use of polymeric chemicals in the construction of dams in Indonesia, where located in tropical region, resulted in health damage. It is prohibited to use all chemical grouting in the country since the accidents. In order to reduce environmental issues, sodium silicate chemicals as lowest toxicity material is commonly used in the chemical grouting. However, there is no application of sodium silicate chemicals in tropical region like Indonesia. From these backgrounds, this research discusses the applicability of the chemical grouting of sodium silicate chemicals in tropical region from the aspects of its functions. In order to discuss its applicability, the chemical grouts injecting test were carried out by using the samples of sands which were collected from Indonesia. Solidification of the chemical grouts were also evaluated by means of various laboratory tests.

\section{$2 \quad$ Material}

\subsection{Chemical Grout}

The chemical grouts consist of two kinds of liquids (Liquid A and Liquid B). Liquid A is mainly composed of sodium silicate. Liquid B is composed with water and reactant. A certain amount of time is required for the chemical grouts to be solidified after mixing the liquids A and B with each other. This time is called gelling time. Solidification of chemical grouts occurs by reaction of sodium silicate of liquid A and acid contained in reactant of liquid B to form a polymer. The reaction formula is shown as (1).

$$
\mathrm{Na}_{2} \mathrm{O} \cdot \mathrm{nSiO}{ }_{2}+2 \mathrm{NaHCO}_{3} \rightarrow 2 \mathrm{Na}_{2} \mathrm{CO}_{3}+\mathrm{nSiO}_{2}+\mathrm{H}_{2} \mathrm{O}
$$

As shown in Equation (1), gelling time depends on the amount of sodium silicate contained in liquid A and the amount of acid contained in liquid B. In this study, chemical grouts with different gelling time are prepared by arranging the ratio of liquids A and B: chemical grout with gelling time of several seconds (Type 1) and several minutes (Type 2) were used. Table 1 shows the components of reactants contained in liquid B. Table 2 and Table 3 show the composition of chemical grout and the results of gelling time measurement respectively. Based on the results of gelling 
time, it is expected that Type 1 can be used for improving the ground with high permeability due to rapid gelling time. On the other hands, Type 2 can be used to improve the ground with low permeability because it has a longer gelling time.

From the above, this study focuses on the construction as shown in Fig. 2. Chemical grout with rapid gelling time is injected as primary injection for sealing around the injection pipe and reducing the influence of ground water by roughly grouting. After that, chemical grout with a longer gelling time is injected as secondary injection for fully ground improvement in a wide area where the primary injection is performed.

Table 1. Reactants composition of liquid B.

\begin{tabular}{lll}
\hline & $\mathrm{NaHCO}_{3}$ & $\mathrm{KHCO}_{3}$ \\
\hline Reactant I & $60-80 \%$ & $10-30 \%$ \\
Reactant II & $40-60 \%$ & $40-70 \%$ \\
\hline
\end{tabular}

Table 2. Chemical grout composition (Type 1).

\begin{tabular}{lllll}
\hline \multicolumn{2}{l}{ Liquid A $(50 \mathrm{~mL})$} & \multicolumn{3}{c}{ Liquid B $(50 \mathrm{~mL})$} \\
\hline \multirow{2}{*}{ Water } & Sodium silicate & Water & \multicolumn{2}{c}{ Sodium silicate } \\
& & & I & II \\
$51.8 \%$ & $48.2 \%$ & $51.8 \%$ & $48.2 \%$ & $51.8 \%$ \\
\hline
\end{tabular}

Table 3. Chemical grout composition (Type 2).

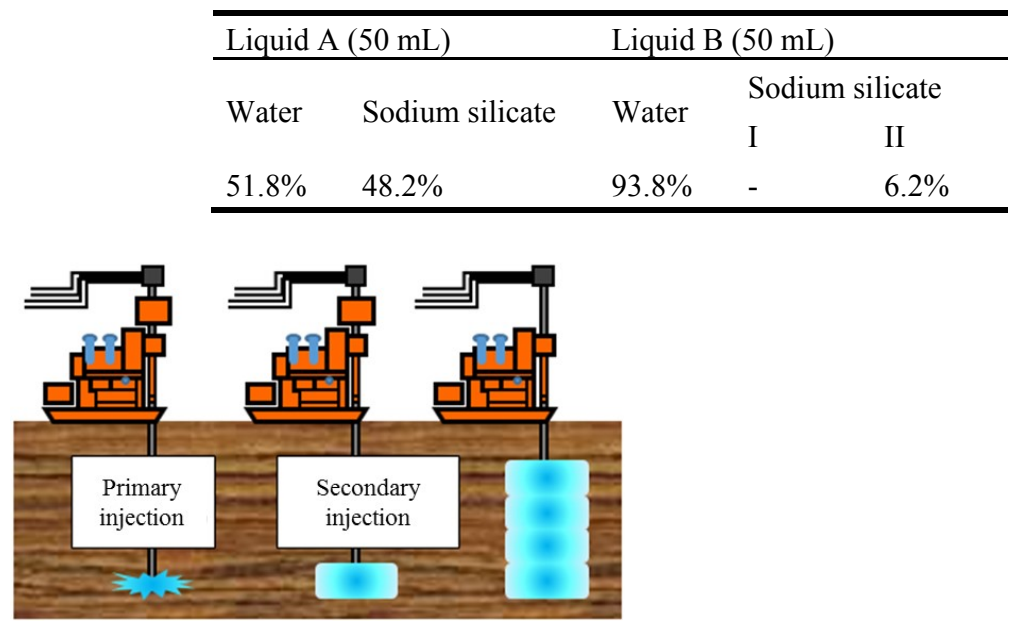

Fig. 2. Chemical grouts are injected into the grounds.

\subsection{Grouted Soil}

In addition to Volcanic Sand collected from the lahar deposit at the foot of the Gunter volcano in Java Island, Clayey Sand simulating the clay-containing soil in Indonesia, and Acid Sand which is adjusted $\mathrm{pH}$ by using sulfuric acid were used. Furthermore, 
Toyoura quartz sand was used as the soil which serves as a standard for improving effects when applying chemicals. The soil properties and particle size distribution are shown in Table 4 and Table 5. These sands were mixed with each of two types of chemical grouts and solidified. They are called as sand gel. A sand gel was prepared by mixing a soil sample and each chemical grout in a mold having an inner diameter of $5 \mathrm{~cm}$ and a height of $10 \mathrm{~cm}$. In each sand gel, $300 \mathrm{~g}$ of soil sample and $100 \mathrm{~mL}$ of chemical grout were used.

Table 4. Permeability of $\mathrm{pH}$ of each sand.

\begin{tabular}{lll}
\hline & $\mathrm{pH}$ & Permeability $(\mathrm{cm} / \mathrm{sec})$ \\
\hline Toyoura Quartz Sand & 7.45 & $6.45 \times 10^{-3}$ \\
Volcanic Sand & 6.94 & $3.42 \times 10^{-3}$ \\
Clayey Sand & 6.27 & $5.43 \times 10^{-3}$ \\
\multirow{2}{*}{ Acid Sand } & 4.07 & $8.87 \times 10^{-3}$ \\
\hline
\end{tabular}

Table 5. Grain size distribution of each sand.

\begin{tabular}{lllll}
\hline & Coarse Sand & Medium Grain Sand & Fine Grain Sand & Clay \\
The Particle Size & $4 \mathrm{~mm}-2 \mathrm{~mm}$ & $2 \mathrm{~mm}-425 \mu \mathrm{m}$ & $425 \mu \mathrm{m}-75 \mu \mathrm{m}$ & Less than $75 \mu \mathrm{m}$ \\
\hline Toyoura Quartz Sand & $0 \%$ & $5 \%$ & $95 \%$ & $0 \%$ \\
Volcanic Sand & $5 \%$ & $50 \%$ & $45 \%$ & $0 \%$ \\
Clayey Sand & $0 \%$ & $40 \%$ & $40 \%$ & $20 \%$ \\
Acid Sand & $5 \%$ & $50 \%$ & $45 \%$ & $0 \%$ \\
\hline
\end{tabular}

\section{$3 \quad$ Laboratory Tests}

\subsection{Hydraulic Conductivity Improvement Analysis}

The falling head hydraulic conductivity test to measure the coefficients of permeability was conducted in order to discuss the function of the chemical grouts from the aspect of improving permeability [3]. Sand gels were cured in water for some curing times in order to understand changes of the coefficients of permeability with time elapsed. Curing times were 1, 7, 14, 28 days. From the construction guidelines of the chemical grouting, if the hydraulic conductivity is higher than $1 \times 10^{-4} \mathrm{~cm} / \mathrm{sec}$, it was judged that there was a water-blocking effect [4].

\section{$4 \quad$ Result and Discussion}

\subsection{Application to Toyoura Quartz Sand}

Fig. 3 shows the results of permeability test in Toyoura quartz sand. From the results, it was confirmed that Type 1 and Type 2 maintain the water-blocking effect for a long 
period of time. In addition, it was confirmed that coefficient of permeability in Type 1 and Type 2 has a value of about $2.5 \times 10^{-5} \mathrm{~cm} / \mathrm{sec}$ on the 28 days after curing in water.

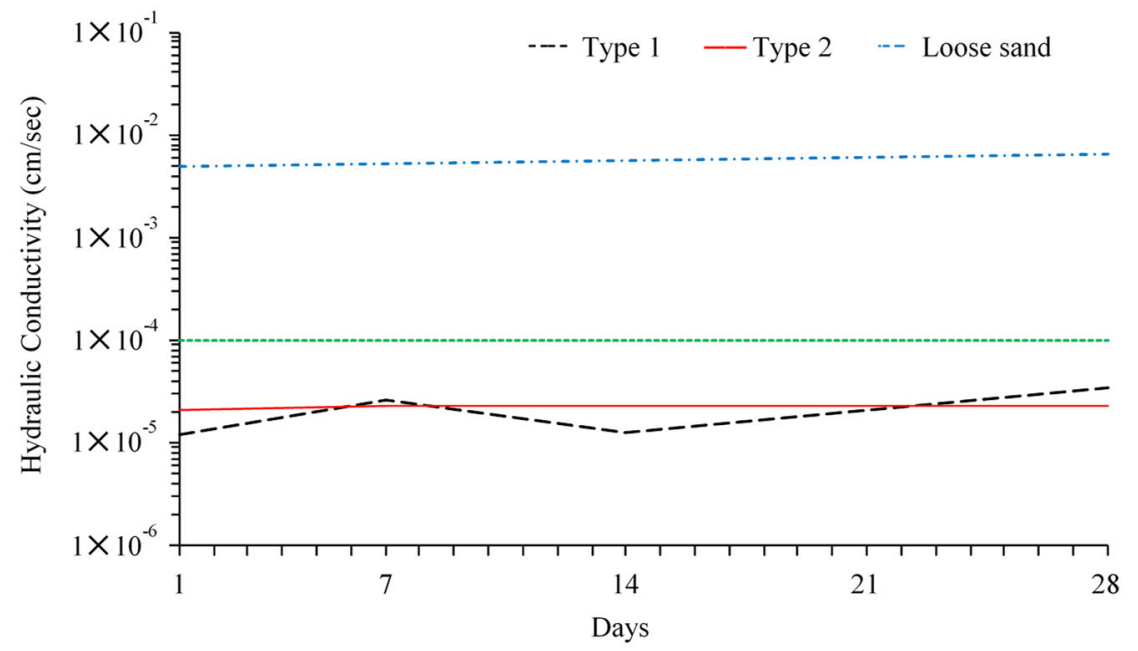

Fig. 3. Hydraulic conductivity performance of sand gels in Toyoura quartz sand.

\subsection{Application to Volcanic Sand}

Fig. 4 shows the results of permeability test in Volcanic sand. From the results, it was confirmed that both of Type 1 and Type 2 in Volcanic sand satisfy the reference value of $1 \times 10^{-4} \mathrm{~cm} / \mathrm{sec}$ which is the construction guideline of the chemical grouting. This fact can be explained that the permeability of the volcanic sand is high because the ratio of a large particle size such as coarse sand and medium grain sand is higher than other soils. Soil having higher permeability allows to penetrate chemical grouts largely. As a result, it seems that it was able to demonstrate the original improvement effect of the chemical grouts. That is, when sodium silicate-based chemical grouting is applied to volcanic sand, sufficient improvement effect can be expected.

\subsection{Application to Clayey Sand}

Fig. 5a shows the results of permeability test in clayey sand. In case of Type 1, the water-blocking effect was similar to that of Toyoura quartz sand. On the other hands, the coefficient of permeability increased with time elapsed and on 28 days after curing in water for Type 2, meaning that the sand gel was not satisfied $1.0 \times 10-4 \mathrm{~cm} / \mathrm{sec}$ defined as the construction standard of the chemical grouting. As described above in Fig. $5 \mathrm{~b}$, the permeability of sand gel of both of Type 1 and Type 2 have to be satisfied $1.0 \times 10-4 \mathrm{~cm} / \mathrm{sec}$ to ensure the water-blocking effect. Therefore, when sodium silicate-based the chemical grouting is applied to soil containing clay content, sufficient consideration is required if the construction period is prolonged. 
It can be considered that the silica elution, which is one of deteriorating factors of sand gel, easily occurred due to the water absorbing action of the clay as a cause of the increase coefficient of the permeability of sand gel. Silica elution is a phenomenon in which the network of gels formed by solidified of the chemical grouts of Equation (1) is destroyed by elution of unreacted silica due to penetration of water. Therefore, as a result of measuring the silica elution amount from each sand gel, it was confirmed that the silica leaching amount was larger in clayey sand than Toyoura quartz sand as shown in Fig. 5b. It is considered that the silica elution tends to occur easily in clayey sand because the clay easily absorbs water, meaning that the water contained clay affects silica elution. Furthermore, it can be confirmed that the silica elution amount is larger in Type 2 than Type 1. It is considered that clay absorbs more water before solidification in Sand gel of Type 2 because the gelling time of Type 2 is longer than that of Type 1. From the above, it was found that the water-blocking effect of the chemical grout is lowered due to the water absorbing action of the clay. For this reason, it is considered necessary to select a chemical grout taking account of the influence of clay when sodium silicate-based chemical grouting is adopted to clayey soil.

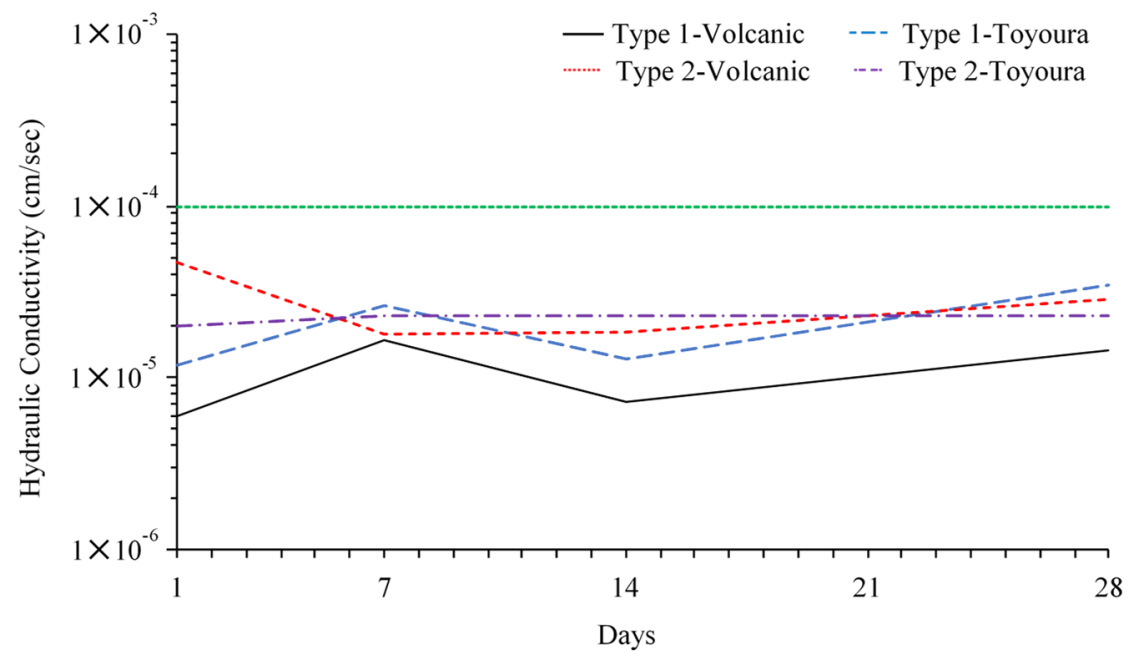

Fig. 4. Hydraulic conductivity performance of sand gels in volcanic sand.

\subsection{Application to Acid Sand}

Fig. 6 shows the results of the permeability test in acid sand. It was confirmed that the water-blocking effect was confirmed for a long period of time in soil $\mathrm{pH}$ equals 2.30 and 4.07 when Type 2 was applied as in the case of applying to Toyoura quartz sand. On the other hand, it was confirmed that the standard value was not satisfied on sand gel to which Type 1 was applied on 7 days after curing in water. This is believed to be due to solidification of the chemical grouts before it penetrates the entire sand gel because the gelling time of the chemical grout is shortened due to the low $\mathrm{pH}$ of soil. Table 6 shows the gelling time of Type 1 and Type 2 when it is applied to acidic 
sands. Normally, a chemical grout forms a polymer by a reaction between sodium silicate and an acidic salt and solidifies, but the reaction between sodium silicate and sulfuric acid is occurred when it is applied to soil whose $\mathrm{pH}$ is adjusted with sulfuric acid, as shown in the Equation (2). Therefore, it is considered that the solidification proceeded faster than usual, and the gelling time became shorter.

$$
\mathrm{Na}_{2} \mathrm{O} \cdot \mathrm{nSiO}_{2}+\mathrm{H}_{2} \mathrm{SO}_{4} \rightarrow \mathrm{nSiO}_{2}+\mathrm{Na}_{2} \mathrm{SO}_{4}+\mathrm{H}_{2} \mathrm{O}
$$

In Type 1, the gelling time could not be accurately measured because it was around a few seconds, but in Type 2, the gelling time is about $50 \%$ of normal in soil $\mathrm{pH}=$ 4.07 and about $20 \%$ of normal in soil $\mathrm{pH}=2.30$. That is, when the instantaneous type is applied in the case where the $\mathrm{pH}$ of the soil is acidic, the original effects of chemical grouting cannot be ensured due to its rapid gelling under acidic conditions. Therefore, it is considered necessary to select a chemical grout in consideration of shortening of gelling time when sodium silicate-based chemical grouting is applied to soil with low $\mathrm{pH}$.

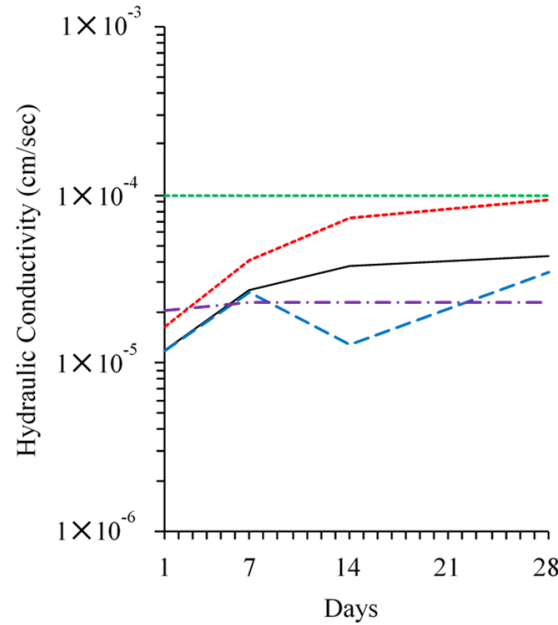

- Type 1-Clayey ---- Type 1-Toyoura -....... Type 2-Clayey ---. Type 2-Toyoura

(a)

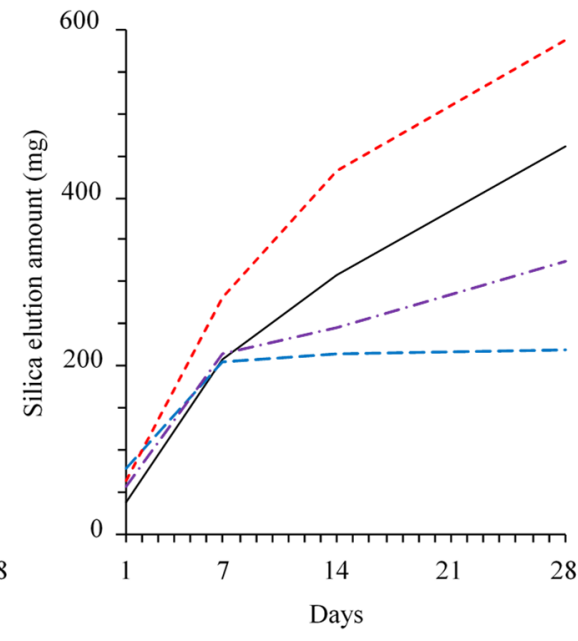

(b)

Fig. 5. (a) Hydraulic conductivity performances of sand gels in clayey sand; (b) Silica elution amount.

Table 6. Gelling time in soil with $\mathrm{pH}=2.3$ and 4.07 .

\begin{tabular}{llll}
\hline $\mathrm{pH}$ & 7.45 & 4.07 & 2.30 \\
\hline Type 1 & $\pm 11 \mathrm{sec}$ & Unmeasurable & Unmeasurable \\
Type 2 & $\pm 160 \mathrm{sec}$ & $\pm 86 \mathrm{sec}$ & $\pm 32 \mathrm{sec}$ \\
\hline
\end{tabular}

$※$ Gelling Time at $\mathrm{pH}=7.45$ is the case of Toyoura 


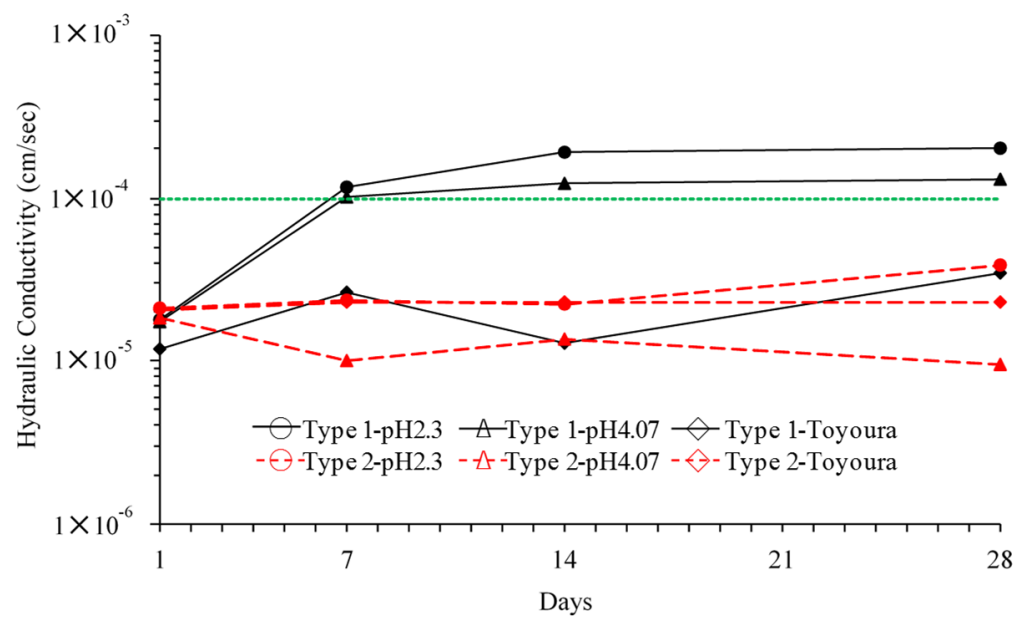

Fig. 6. Hydraulic conductivity performances of sand gels in acid sand.

\section{Conclusion}

In this study, we investigate the applicability of injection method for tropical soil conditions by conducting the falling head hydraulic conductivity test using sand gel prepared by soil samples simulating soil of Indonesia. The major findings are following.

- In the volcanic sand, the sodium silicate-based chemical grouting fully demonstrated the water-blocking effect.

- When applying the sodium silicate-based chemical grouting to clayey soil, it is necessary to select a chemical grout taking account of the influence of clay content.

- When applying the sodium silicate-based chemical grouting to soil with a low soil $\mathrm{pH}$, it is necessary to select a chemical grout taking into consideration the effect of acid.

\section{References}

1. Galvin, J.: Critical role of risk management in ground engineering and opportunities for improvement. International Journal of Mining Science and Technology 27, 725-731 (2017).

2. Pricewaterhouse Coopers LLP: Summary of South East Infrastructure Spending, Outlook to 2025 (2014).

3. American Society for Testing and Materials: Standard Test Method for Expansion and Bleeding of Freshly Mixed Grouts for Preplaced-Aggregate Concrete in the Laboratory, ASTM Standard C 940-10a (2010).

4. Japan Chemical Grouting Association: Design and Policy for Chemical Grouting Construction (1989). 